\title{
Pengaruh Layanan Akademik dan Citra Institusi terhadap Loyalitas Mahasiswa Universitas Terbuka
}

\author{
Zulkarnaini $^{1}$ dan Rhini Fatmasari ${ }^{2}$ \\ Universitas Terbuka \\ email: zulkarnaini@ecampus.ut.ac.id ${ }^{1}$, riens@ecampus.ut.ac.id $^{2}$
}

Received: 09 May 2021; Revised: 26 July 2021; Accepted: 28 August 2021

DOI: http://dx.doi.org/10.37905/aksara.7.3.1285-1294.2021

\begin{abstract}
Abstrak
Loyalitas mahasiswa merupakan perilaku komitmen positif mahasiswa kepada perguruan tinggi yang ditunjukkan dengan kesetiaan dan keikutsertaan dalam proses pendidikan. Loyalitas merupakan upaya membangun suatu citra sejati, yang bukan sekedar nama, pelayanan yang berkualitas merupakan salah satu faktor yang sangat berpengaruh terhadap loyalitas. Kualitas pelayanan menentukan eksistensi dan kekuatan sebuah citra dan brand. Pelanggan yang puas karena menerima pelayanan yang baik akan merasa senang. Oleh karena itu, setiap saat mereka akan kembali dan menjadi pelanggan loyal.

Penelitian ini bertujuan untuk menguji pengaruh layanan akademik dan citra institusi terhadap loyalitas mahasiswa UT. Hasil penelitian menujukkan bahwa terdapat pengaruh langsung layanan akademik terhadap loyalitas mahasiswa dengan koefisien path sebesar 0.392. Citra institusi juga berpengaruh secara 1;angsung terhadap loyalitas mahasiswa dengan koefisien path sebesar 0.450, sementara citra institusi juga berpengaruh terhadap loyalitas mahasiswa dengan koefisien path sebesar 0.450. Penelitian ini juga menjelaskan bahwa layanan akademik dan citra institusi secara bersana-sama berpengaruh terhadap loyalitas mahasiswa.
\end{abstract}

Kata Kunci : pelayanan yang berkualitas, citra institusi, loyalitas mahasiswa UT

\section{PENDAHULUAN}

Universitas Terbuka (UT) merupakan lembaga pendidikan tinggi yang menyelenggarakan pendidikan terbuka dan jarak jauh dengan pemberian layanan pendidikan yang meniadakan kendala tempat, waktu, dan aspek yang disebabkan oleh karakteristik mahasiswa (Bates, A. W., \& Bates, 2005) Nomor 12 Tahun 2012 tentang Pendidikan Tinggi, mendorong PT di Indonesia untuk menawarkan program studi dengan dua sistem, yaitu tatap muka dan program pembelajaran jarak jauh dalam bentuk e-learning programs (Depdikbud, 2012). Hal ini menjadikan UT tidak lagi merupakan satu-satunya penyedia jasa pendidikan tinggi jarak-jauh di Indonesia.

Sebaran mahasiswa UT berada pada 39 Unit Program Belajar Jarak Jauh (UPBJJ) di seluruh Indonesia. Pada tahun 2019.2 jumlah mahasiswa aktif UT 312.656 orang. UT tidak menerapkan sistem drop out (DO) pada mahasiswanya, sehingga keinginan mahasiswa untuk melanjutkan studi di UT sangat tergantung pada tingkat kepuasan yang diperoleh terhadap layanan akademik UT dan loyalitas mereka terhadap Institusi 
UT. Sehingga salah satu faktor yang harus terus menerus dipertahankan oleh UT adalah kualitas layanan dan citra institusi di mata mahasiswa. Turun naiknya jumlah mahasiswa dipengaruhi image masyarakat yang akan menjadi calon mahasiswa terhadap keberadaan UT itu sendiri. Image positif tentu akan berdampak positif terhadap citra UT sebagai institusi dan begitu juga sebaliknya.

Loyalitas konsumen adalah kesetiaan konsumen yang dipresentasikan dalam pembelian yang konsisten terhadap produk atau jasa sepanjang waktu dan ada sikap yang baik untuk merekomendasikan orang lain untuk membeli produk. Loyalitas merupakan derajat sejauh mana seorang konsumen menunjukkan perilaku pembelian berulang dari suatu penyedia jasa, memiliki suatu desposisi atau kecenderungan sikap positif terhadap penyedia jasa, dan hanya mempertimbangkan untuk menggunakan penyedia jasa ini pada saat muncul kebutuhan untuk memakai jasa ini (Gramer dan Brown, 2006). Sementara Oliver (Taylor, Steven. A., Celuch, Kevin, 2004) menjelaskan loyalitas sebagai komitmen yang tinggi untuk membeli kembali suatu produk atau jasa yang disukai di masa mendatang, disamping pengaruh situasi dan usaha pemasar dalam merubah perilaku.

Mahasiswa merupakan salah satu pelanggan yang harus dilayani untuk mendapatkan jasa pendidikan yang berkualitas. Perguruan tinggi seharusnya menyusun strategi menarik mereka sehingga menjadi pelanggan yang loyal (customer loyalty). Loyalitas pelanggan dipengaruhi oleh kepuasan, rintangan dan keluhan pelanggan. Indikator loyalitas pelanggan menurut Tjiptono (2011) adalah retention, repeat and referral. Retention adalah kebal terhadap jasa/produk tertentu karena memiliki kesan yang positif sehingga tidak tertarik pada jasa/produk lain. Repeat merupakan perilaku pembelian kembali atas hasil produk barang yang dibeli dari perusahaan tertentu. Referral adalah rekomendasi positif kepada orang lain tentang produk yang dipakai. Loyalitas erat hubungannya dengan konsep pelayanan pelanggan. Hubungan yang erat ini dapat digambarkan sebagai berikut.

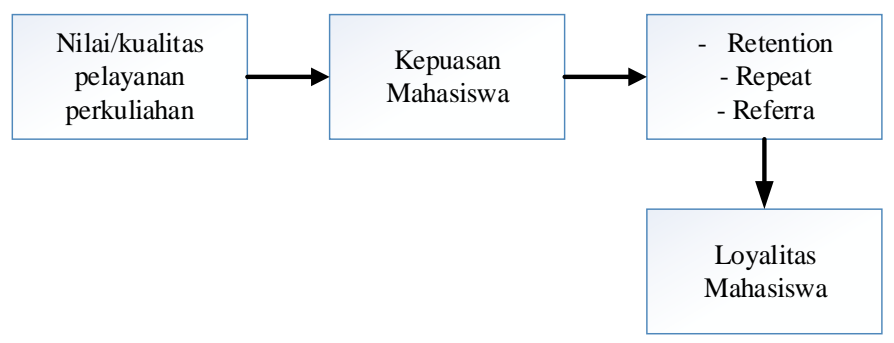

Gambar 1. Hubungan Kepuasan Mahasiswa dengan Loyalitas

Layanan pelanggan secara mendasar adalah jantung dan jiwa dari brand (E Knapp, 2000). Artinya, kualitas pelayanan menentukan eksistensi dan kekuatan sebuah citra. Pelanggan yang puas karena menerima pelayanan yang baik akan merasa senang. Oleh karena itu, setiap saat mereka akan kembali dan menjadi pelanggan loyal. (Kotler, 2003) menyatakan bahwa suatu konsep brand atau citra yang ingin dibangun, tidak akan terwujud bila tidak didukung upaya setiap orang dalam perusahaan tersebut. Tosti dan Stotz sebagaimana dikutip Kotler (2003), menyatakan bahwa terlalu banyak perusahaan 
membuat janji-janji dengan brand-nya, tetapi gagal untuk melatih para pegawainya memahami dan menepati janji-janji brand tersebut.

Salah satu variable yang berpengaruh terhadap loyalitas adalah citra institusi. Canton (2004) menjelaskan bahwa citra adalah kesan, perasaan, gambaran dari publik terhadap perusahaan; kesan yang dengan sengaja diciptakan dari suatu objek, orang atau organisasi. Jefkins (1998) mengartikan citra sebagai kesan sebagai kesan, gambaran atau impresi yang tepat (sesuai dengan kenyataan yang sebenarnya) mengenai berbagai kebijakan, personel, produk, atau jasa-jasa suatu organisasi atau perusahaan. Jefkins (1998) membagi citra (1) mirror image (citra bayangan); (2) current image (citra yang berlaku); (3) multiple image (citra majemuk); (4) corporate image (citra perusahaan); dan (5) wish image (citra yang diharapkan.

Sama halnya dengan organisasi bisnis, citra juga perlu dibangun pada organisasi publik, seperti Perguruan Tinggi, agar tetap selalu diminati oleh masyarakat dan mendapatkan penilaian positif dari stakeholdersnya. Pada Perguruan Tinggi, pelanggannya adalah mahasiswa dan calon mahasiswa serta stakeholders yang meliputi, masyarakat, orang tua, pemerintah, alumni, dan investor. Citra yang ingin dibentuk oleh sebuah perguruan tinggi tentunya berkaitan erat dengan mutu pelayanan dan kualitas pembelajaran yang nantinya akan berdampak pada kualitas lulusan sehingga akan dapat menumbuhkan kepercayaan bagi masyarakat ataupun stakeholders yang akan menjadi pengguna lulusan tersebut. Citra perguruan tinggi sebagai salah satu faktor dalam meningkatkan daya saing, merupakan salah satu elemen kunci intangible resources yang akan menjadi sumber penciptaan kondisi keunggulan bersaing berkelanjutan suatu perusahaan (Rahayu, 2009). Salah satu indikator dalam meraih kepercayaan konsumen (mahasiswa) adalah tingkat kepuasan (satisfaction) yang mereka peroleh.

Persepsi pelanggan terhadap kualitas pelayanan adalah perbedaan antara apa yang mereka perolah dan apa yang mereka harapan (Michael LeBpeuf, 1992). Pendekatan mutu pelayanan dan jasa yang banyak digunakan adalah model ServQual yang dibangun dengan membandingkan dua faktor utama yaitu layanan yang diterima dengan harapan konsumen (Tjiptono, Fandy dan Gregorius, 2011).

Citra institusi perlu diciptakan agar bernilai positif (Katx, 1994). Citra terbentuk berdasarkan pengetahuan dan informasi-informasi yang diterima oleh seseorang. Sebagaimana yang dikatakan oleh John S Nimpoeno, bahwa proses pembentukan citra terbentuk melalui pengalaman atau stimulus yang berasal dari luar diorganisasikan dan mempengaruhi respons (Soleh Soemirat dan Elvinaro Ardianto, 2007).

Proses pembentukan citra pada akhirnya akan menghasilkan sikap, pendapat, tanggapan, atau perilaku tertentu. Kenyatan menunjukkan bahwa perusahaanperusahaan yang memiliki citra dan reputasi yang bagus, umumnya memiliki enam hal berikut untuk meningkatkan citra di mata publik, yaitu : (1) hubungan yang baik dengan para pemuka masyarakat; (2) hubungan positif dengan pemerintah setempat; (3) rasa kebanggaan dalam organisasi dan diantara khlalayak sasaran; (4) saling pengertian antara khalayak sasaran, baik internal maupun eksternal dan (6) meningkatkan kesetiaan para staf perusahaan (Anggoro, 2001). Soleh Soemirat dan Elvinaro Ardianto (2007) lebih lanjut mengungkapkan secara teoritis proses pembentukan citra dalam struktur 
kognitif hampir sama dengan pengertian sistem komunikasi. Secara lengkap, proses pembentukan citra tersebut dapat dilihat pada Gambar 2.2 berikut.

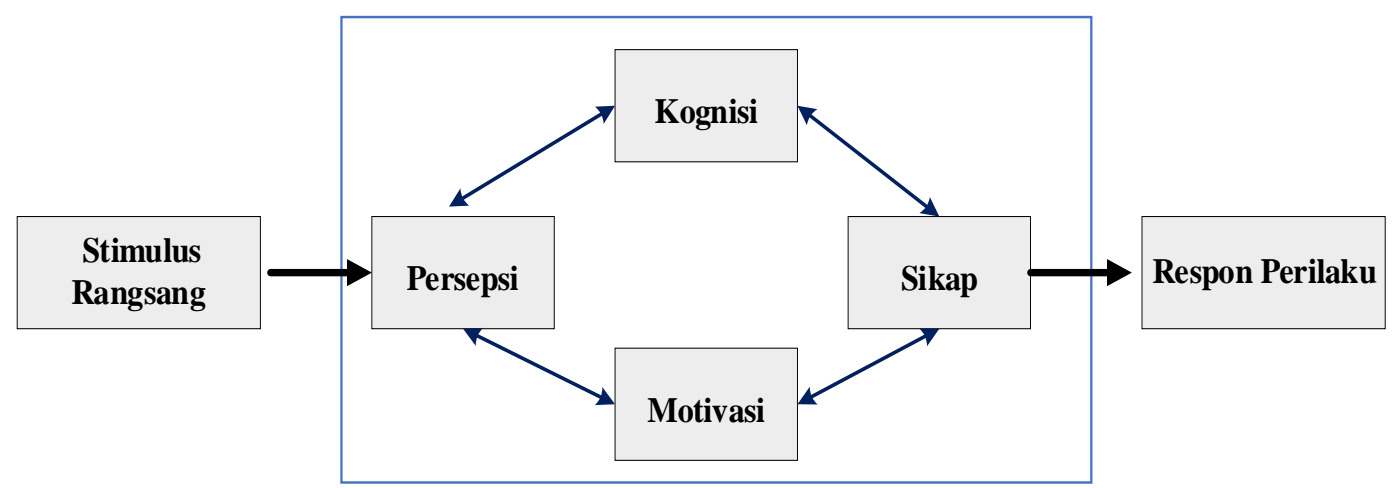

Gambar 2. Model Pembentukan Citra Pengalaman Stimulus

Layanan akademik merupakan " $a$ teaching and learning strategy that integrates meaningful community service with instruction and reflection to enrich the learning experience, teach civic responsibility, and strengthen communities. Para ahli (Honnet and Poulsen, 1989; Howard, 1993; Jacoby and Associates, 1996; Kendall and Associates, 1986; Rhoads, 1997) menjelaskan enam elemen kunci layanan akademik. Tiga dari elemen lebih fokus pada sisi community dan tiga elemen fokus pada sisi kampus. Sisi community meliputi : meaningful service (work), meets a need or goal. Pada sisi campus berupa layanan pada mahasiswa berkaitan dengan tujuan pendidikan, integrasi layanan pendidikan dengan model evaluasi dan layanan perbaikan pembelajaran (Weigert, 1998).

Layanan akademik disediakan Universitas untuk para stakeholder (Sihombing, 2002) yang terdiri dari: a) pelanggan eksternal primer, yaitu mahasiswa sebagai peserta pendidik; b) pelanggan eksternal sekunder, yaitu pihak yang membiayai pendidikan; c) mahasiswa, meliputi orang tua, saudara, wali, atau pemberi beasiswa; dan d) pelanggan eksternal tersier, yaitu meliputi pasar tenaga kerja dari pemerintah dan masyarakat secara luas; serta e) pelanggan internal, yaitu seluruh dosen, staf, dan karyawan.

Saat ini UT memiliki jumlah mahasiswa 296.477 orang yang tersebar di 39 Unit Pembelajaran Jarak Jauh (UPBJJ) UT. Model pembelajaran dan layanan akademik yang diterapkan adalah pembelajaran online (Marc J Rosenberg, 2001); (Dietmar K Kennepohl, 2019). UT menerapkan pembelajaran online dengan tujuan meningkatkan interaktivitas mahasiswa dengan materi ajar, meningkatkan interaksi antara mahasiswa dengan dosen (tutor), juga interaksi antarmahasiswa itu sendiri (Belawati, 2003). Elearning di UT diterapkan dalam beberapa jenis layanan, berupa pemberian bahan ajar suplemen berbasis web (web suplemen), tutorial berbasis jaringan (web based tutorial) yang dikenal dengan online tutorial, latihan mandiri, kit tutorial, dan lainnya (Tim Rektorat, 2012). Sebagai layanan yang menunjang layanan akademik, UT juga memberikan layanan mahasiswa dalam bentuk layanan administrasi, yang difokuskan pada pemberian bantuan kepada mahasiswa dalam registrasi, mendapatkan bahan ajar, alih kredit, dan hal-hal lain yang dapat memengaruhi proses belajar mahasiswa (Tim Rektorat, 2012). 
Bertolak dari beberapa anggapan diatas menujukkan bahwa layanan akademik dan citra institusi merupakan faktor yang penting dalam pembentukan loyalitas mahasiswa sehingga mereka akan memilih UT sebagai tempat studi mereka. Sehingga diperlukan satu penelitian untuk mengkaji bagaimana persepsi dan kepuasan mahasiswa terhadap layanan akademik yang diberikan oleh UT dan citra UT di mata mahasiswa terhadap loyalitas mereka untuk melanjutkan studi di Universitas Terbuka.

\section{METODE PENELITIAN}

Secara umum penelitian ini bertujuan untuk memperoleh informasi mengenai pengaruh layanan akademik dan citra institusi terhadap loyalitas mahasiswa. Studi penelitian ini dilakukan pada mahasiswa Universitas Terbuka yang mendapat pelayanan di 3 (Tiga) UPBJJ besar di Indonesia. Dalam penelitian ini metode yang digunakan adalah metode field research melalui penelitian survey kausal dengan analisis regresi dan teknik korelasional. Penyusunan rancangan penelitian, statistik sebagai pengolahan dan analisis data adalah untuk melihat pengaruh antara variabel independen dan dependennya.

Populasi penelitian adalah mahasiswa Universitas Terbuka di 3 (Tiga) UPBJJ UT yaitu di UPBJJ UT Jakarta dan UPBJJ UT Purwokerto dan UPBJJ UT Lampung . Jumlah kuesioner yang kembali dan diolah sejumlah 191 mahasiswa. 40,31\% responden berprofesi sebagai guru, dengan rentang usia terbesar 18-25 tahun $(46,60 \%)$.

\section{HASIL DAN PEMBAHASAN}

Deskripsi data pada bagian ini meliputi data variabel Y (loyalitas mahasiswa) sebagai variabel terikat (endogenous), variabel X1 (layanan akademik) dan variabel X2 (citra institusi) sebagai variabel bebas (exsogenous). Layanan akademik yang diujikan pada penelitian ini adalah berkaiatan dengan (a) Modul; (b) Tutorial Online; (c) Proses alih kredit; (d) Pelaksanaan UAS; (e) UAS dengan Sistem Ujian Online; (f) Nilai Akhir Semester melalui website UT; (g) Kemudahan menghubungi Program Studi; (h) Proses pembimbingan akademik; (i) Pengaduan secara langsung dan melalui layanan online; (j) Proses Registrasi; (k) Pelaksanaan TTM; (l) Kompetensi Tutor; (m) Informasi mengenai waktu dan lokasi UAS; (n) Kemudahan memperoleh Kartu Hasil Studi/ LKAM; (o) Kemudahan menghubungi UPBJJ.

Data telah memenuhi uji Normalitas, Uji Autokorelasi, dan Uji Homoskedastisitas.

\section{Pengujian Hipotesis}

Hipotesis Pertama : Terdapat pengaruh langsung positif layanan akademik (X1) terhadap loyalitas mahasiswa UT (Y)

Layanan Akademik berpengaruh langsung positif terhadap loyalitas mahasiswa. Dari hasil perhitungan analisis jalur, pengaruh langsung layanan akademik terhadap loyalitas mahaasiswa, nilai koefisien jalur sebesar 0.392 dimana nilai koefisien $t_{\text {hitung }}$ sebesar 6,410. Nilai Koefisien tabel untuk $\alpha=0,05$ sebesar 1,96. Oleh karena nilai koefisien thitung lebih besar dari pada nilai tabel maka dengan demikian Ho ditolak dan H1 diterima yaitu bahwa layanan akademik berpengaruh secara langsung terhadap loyalitas mahasiswa dapat diterima. Meningkatnya citra institusi akan mengakibatkan peningkatan layanan akademik sebesar 39,2\%. 
Hipotesis Kedua : Terdapat pengaruh langsung positif citra institusi (X2) terhadap loyalitas mahasiswa UT (Y)

Dari hasil perhitungan analisis jalur, pengaruh langsung citra institusi terhadap loyalitas mahasiswa, nilai koefisien jalur sebesar 0,450 dan nilai koefisien $t_{\text {hitung }}$ sebesar 7,362 sedangkan nilai koefisien $t_{\text {tabel }}$ untuk $\alpha=0,05$ sebesar 1,96. Oleh karena nilai koefisien $t_{\text {hitung }}$ lebih besar dari pada nilai koefisien $t_{\text {tabel }}$ maka Ho ditolak dan Hi diterima.

Meningkatnya citra institusi akan mengakibatkan peningkatan loyalitas mahasiswa sebesar 45\%. Hasil pengujian Hipotesis 1dan Hipotesis 2 ditampilkan pada tabel berikut.

\begin{tabular}{|c|c|c|c|c|c|c|c|c|c|c|}
\hline \multirow[b]{3}{*}{ Model } & \multirow[b]{3}{*}{$\mathrm{R}$} & \multicolumn{8}{|c|}{ Model Summary } & \multirow[b]{3}{*}{$\begin{array}{l}\text { Durbin- } \\
\text { Watson }\end{array}$} \\
\hline & & & & & \multicolumn{5}{|c|}{ Change Statistics } & \\
\hline & & $\begin{array}{c}\mathrm{R} \\
\text { Square }\end{array}$ & $\begin{array}{c}\text { Adjusted } \\
\text { R } \\
\text { Square }\end{array}$ & $\begin{array}{l}\text { of the } \\
\text { Estimate }\end{array}$ & $\begin{array}{c}\mathrm{R} \\
\text { Square } \\
\text { Change }\end{array}$ & $\begin{array}{c}\mathrm{F} \\
\text { Change }\end{array}$ & df1 & df2 & $\begin{array}{c}\text { Sig. F } \\
\text { Change }\end{array}$ & \\
\hline 1 & $.753^{\mathrm{a}}$ & .567 & .562 & .01847465 & .567 & 117.951 & 2 & 180 & .000 & 1.653 \\
\hline
\end{tabular}

a. Predictors: (Constant), CI, LA

b. Dependent Variable: Loyal

\begin{tabular}{|ll|l|l|l|l|l|}
\hline \multicolumn{2}{|c|}{ Model } & $\begin{array}{l}\text { Sum of } \\
\text { Squares }\end{array}$ & \multicolumn{1}{|c|}{ df } & $\begin{array}{c}\text { Mean } \\
\text { Square }\end{array}$ & \multicolumn{1}{c|}{$\mathrm{F}$} & Sig. \\
\hline 1 & Regression & .081 & 2 & .040 & 117.951 & $.000^{\mathrm{b}}$ \\
& Residual & .061 & 180 & .000 & & \\
& Total & .142 & 182 & & & \\
\hline
\end{tabular}

a. Dependent Variable: Loyal

b. Predictors: (Constant), CI, LA

\begin{tabular}{|c|c|c|c|c|c|c|c|c|}
\hline \multicolumn{9}{|c|}{ Coefficients } \\
\hline & \multirow[t]{2}{*}{ Model } & \multicolumn{2}{|c|}{$\begin{array}{l}\text { Unstandardized } \\
\text { Coefficients }\end{array}$} & $\begin{array}{c}\text { Standardized } \\
\text { Coefficients }\end{array}$ & \multirow[t]{2}{*}{$\mathrm{t}$} & \multirow[t]{2}{*}{ Sig. } & \multicolumn{2}{|c|}{ Collinearity Statistics } \\
\hline & & $\mathrm{B}$ & Std. Error & Beta & & & Tolerance & VIF \\
\hline \multirow[t]{3}{*}{1} & (Constant) & 1.090 & .021 & & 51.140 & .000 & & \\
\hline & LA & .052 & .008 & .392 & 6.410 & .000 & .643 & 1.555 \\
\hline & $\mathrm{CI}$ & 146.193 & 19.857 & .450 & 7.362 & .000 & .643 & 1.555 \\
\hline
\end{tabular}

a. Dependent Variable: Loyal

Hipotesis Ketiga: Terdapat pengaruh langsung positif layanan akademik (X1) terhadap citra institusi (X2)

Dari hasil perhitungan analisis jalur, pengaruh langsung layanan akademik terhadap citra institusi, nilai koefisien jalur sebesar 0,596 dimana nilai koefisien $t_{\text {hitung }}$ sebesar 10,201. Oleh karena nilai koefisien $t_{\text {hitung }}$ lebih besar dari pada nilai $t_{\text {tabel }}$ maka dengan demikian Ho ditolak dan Hi diterima yaitu bahwa layanan akademik berpengaruh secara langsung terhadap citra institusi. Meningkatnya layanan akademik akan mengakibatkan peningkatan citra institusi sebesar 59,6\%. 


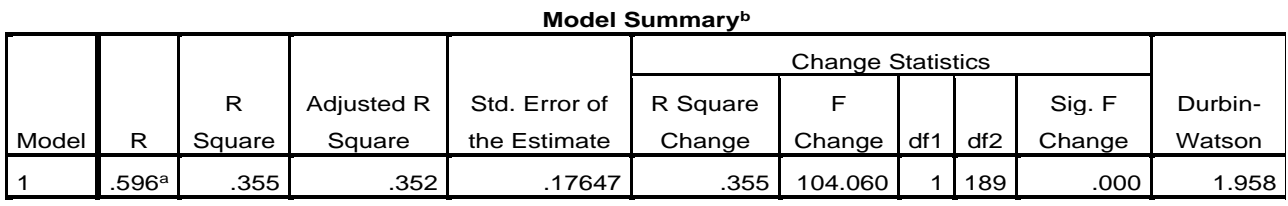

a. Predictors: (Constant), Citra_Institusi

b. Dependent Variable: SQRT_Y1

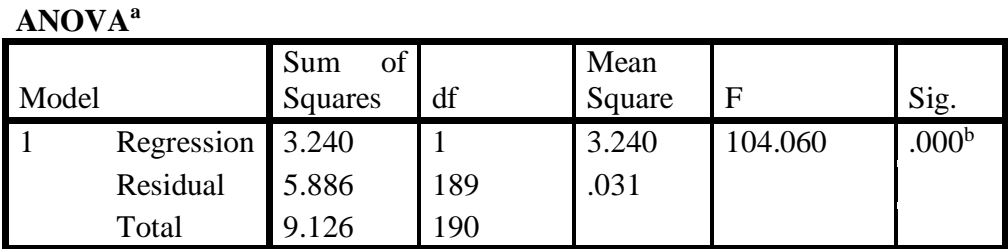

a. Dependent Variable: SQRT_Y1

b. Predictors: (Constant), Citra_Institusi

Coefficients $^{\mathrm{a}}$

\begin{tabular}{|c|c|c|c|c|c|c|c|c|}
\hline & \multirow{2}{*}{ Model } & \multicolumn{2}{|c|}{$\begin{array}{l}\text { Unstandardized } \\
\text { Coefficients }\end{array}$} & \multirow{2}{*}{$\begin{array}{c}\begin{array}{c}\text { Standardized } \\
\text { Coefficients }\end{array} \\
\text { Beta }\end{array}$} & \multirow[t]{2}{*}{$t$} & \multirow[t]{2}{*}{ Sig. } & \multicolumn{2}{|c|}{ Collinearity Statistics } \\
\hline & & $\mathrm{B}$ & Std. Error & & & & Tolerance & VIF \\
\hline 1 & $\begin{array}{l}\text { (Constant) } \\
\text { Citra_Institusi }\end{array}$ & $\begin{array}{l}.875 \\
.270\end{array}$ & $\begin{array}{l}.038 \\
.026\end{array}$ & .596 & $\begin{array}{l}22.930 \\
10.201\end{array}$ & $\begin{array}{l}.000 \\
.000\end{array}$ & 1.000 & 1.000 \\
\hline
\end{tabular}

a. Dependent Variable: SQRT_Y1

Hipotesis Keempat :Terdapat pengaruh secara bersama-sama citra institusi (X1) dan layanan akademik (X2) terhadap loyalitas mahasiswa (Y).

Dari hasil perhitungan analisis jalur, pengaruh secara bersama-sama layanan akademik dan citra institusi terhadap loyalitas mahasiswa diperoleh nilai $\mathrm{R}$ sebesar 0,753 . Sehingga Ho ditolak dan Hi diterima yaitu bahwa layanan akademik dan citra institusi berpengaruh terhadap loyalitas mahasiswa dapat diterima. Hasil pengujian teersebut ditampilkan pada tabel berikut.

\begin{tabular}{|l|r|r|r|r|r|r|r|r|r|r|}
\hline \multirow{2}{*}{ Model } & \multirow{2}{*}{$\mathrm{R}$} & \multirow{2}{*}{ R Square } & \multirow{2}{*}{$\begin{array}{c}\text { Adjusted } \\
\text { R Square }\end{array}$} & \multirow{2}{*}{$\begin{array}{c}\text { Std. Error of } \\
\text { the Estimate }\end{array}$} & $\begin{array}{c}\text { R Square } \\
\text { Change }\end{array}$ & $\begin{array}{c}\text { F } \\
\text { Change }\end{array}$ & df1 & df2 & $\begin{array}{c}\text { Sig. F } \\
\text { Change }\end{array}$ & $\begin{array}{c}\text { Durbin- } \\
\text { Watson }\end{array}$ \\
\hline 1 & $.753^{\mathrm{a}}$ & .567 & .562 & .01847465 & .567 & 117.951 & 2 & 180 & .000 & 1.653 \\
\hline
\end{tabular}

a. Predictors: (Constant), CI, LA

b. Dependent Variable: Loyal

\begin{tabular}{|c|c|c|c|c|c|c|}
\hline \multicolumn{7}{|c|}{ ANOVA $^{a}$} \\
\hline & Model & $\begin{array}{c}\text { Sum of } \\
\text { Squares }\end{array}$ & df & $\begin{array}{l}\text { Mean } \\
\text { Square }\end{array}$ & $F$ & Sig. \\
\hline \multirow[t]{3}{*}{1} & Regression & .081 & 2 & \multirow{3}{*}{$\begin{array}{l}.040 \\
.000\end{array}$} & \multirow[t]{3}{*}{117.951} & \multirow[t]{3}{*}{$.000^{\mathrm{b}}$} \\
\hline & Residual & .061 & 180 & & & \\
\hline & Total & .142 & 182 & & & \\
\hline
\end{tabular}

a. Dependent Variable: Loyal

b. Predictors: (Constant), CI, LA 
Coefficients $^{\mathbf{a}}$

\begin{tabular}{|c|c|c|c|c|c|c|c|}
\hline \multirow{2}{*}{ Model } & \multicolumn{2}{|c|}{ Unstandardized Coefficients } & \multirow{2}{*}{$\begin{array}{c}\text { Standardized Coefficients } \\
\text { Beta }\end{array}$} & \multirow{2}{*}{$\mathrm{t}$} & \multirow{2}{*}{ Sig. } & \multicolumn{2}{|c|}{ Collinearity Statistics } \\
\hline & B & Std. Error & & & & Tolerance & VIF \\
\hline 1 (Constant) & 1.090 & .021 & & 51.140 & .000 & & \\
\hline LA & .052 & .008 & .392 & 6.410 & .000 & .643 & 1.555 \\
\hline CI & 146.193 & 19.857 & .450 & 7.362 & .000 & .643 & 1.555 \\
\hline
\end{tabular}

a. Dependent Variable: Loyal

Hasil Analisis Jalur pengujian hipotesis dapat digambarkan sebagai berikut.

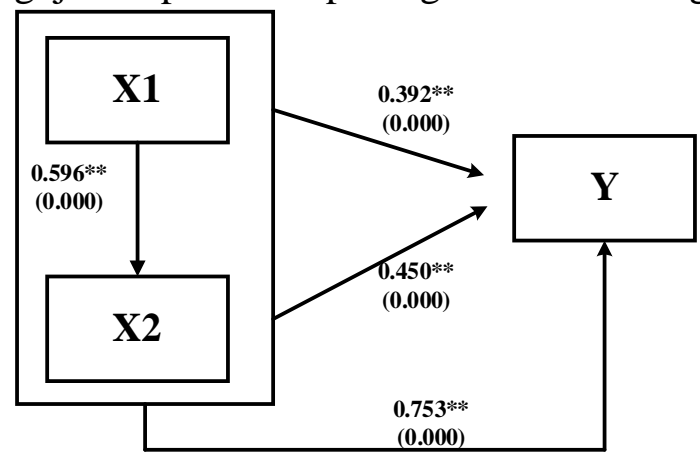

Gambar 4. Model Akhir Hipotetik Analisis Jalur

\section{Diskusi}

Berdasarkan hasil penelitian dapat dijelaskan bahwa citra institusi dan layanan akademik sangat berpengaruh terhadap loyalitas mahasiswa UT dengan tingkat pengaruh $75,3 \%$. Layanan UT dalam bentuk pendidikan terbuka dan jarak jauh secara online dapat diterima dengan baik oleh mahasiswa. Layanan akademik UT juga berpengaruh secara signifikan terhadap citra institusi. Citra tersebut terbentuk berdasarkan pengetahuan dan informasi-informasi yang diterima oleh mahasiswa (Katx, 1994). Layanan akademik dan citra institusi mahasiswa terhadap UT mempengaruhi loyalitas mahasiswa. Hal ini sejalan dengan yang dinayatakan Marconi (1998) dalam Utomo (2006) bahwa salah satu faktor yang berpengaruh terhadap loyalitas adalah citra/ reputasi penyedia layanan. Mahasiswa yang puas dengan layanan dan citra institusi UT akan kembali melakukan registrasi pada semester berikutnya dan memberikan rekomendasi kepada orang lain untuk kuliah di UT (Ciptono, 2001). Indikator loyalitas mahasiswa meliputi : retention, referral dan repeat. Retention terlihat dari sikap mahasiswa yang kebal terhadap jasa pendidikan dari Perguruan Tinggi lain dan tidak tertarik untuk melanjutkan pendidikan ke Perguruan Tinggi lain serta memiliki kepedulian untuk membela jurusan; bersedia memberikan rekomendasi positif tentang kualitas jasa pendidikan yang dirasakan sehingga orang lain menjadi tertarik dan terdorong untuk mendaftar; dan tertarik untuk melanjutkan kembali pendidikan ke jenjang lebih tinggi pada jurusan atau perguruan tinggi yang telah ditempuh dan rasa bangga menjadi alumni.

Penelitian ini sejalan dengan penelitian Arwanda, N. O. D., Hartoyo, H., \& Hartoyo (2013) bahwa citra memiliki pengaruh tertinggi terhadap loyalitas mahasiswa, 
dengan pengaruh dua kali lipat dibandingkan pengaruh kepuasan terhadap loyalitas. Penelitian secara khusus terhadap mahasiswa UT menujukkan kepuasan mahasiswa terhadap layanan akademik UT (Arifah Bintarti, Djoko Rahardjo, 2018). Layanan akademik dalam bentuk tutorial online yang juga berpengaruh terhadap kepuasan dan loyalitas mahasiswa walaupun tidak dominan.

\section{SIMPULAN}

Berdasarkan penelitian yang dilakukan dapat disimpulkan bahwa (a) Layanan akademik yang diberikan oleh UT kepada mahasiswa sangat penting diperhatikan karena tinggi rendahnya layanan akademik akan berpengaruh terhadap loyalitas mahasiswa. Artinya semakin tinggi kualitas layanan akademik yang diberikan baik di UT Pusat maupun di UPBJJ, maka retensi, referral, dan repeat mahasiswa juga akan meningkat; (b) Citra institusi berupa kepercayaan, reputasi, dan domain lembaga merupakan salah satu variabel yang juga berpengaruh terhadap loyalitas mahasiswa. Agar mahasiswa UT loyal, maka perlu peningkatan pada citra institusi. (c) UT perlu memperhatikan layanan akademik yang merupakan salah satu kunci dalam meningkatkan loyalitas mahasiswa, dan selanjutnya berpengaruh terhadap citra institusi.

\section{DAFTAR PUSTAKA}

Anggoro, M. L. (2001). Teori dan Profesi Kehumasan. Jakarta : Bina Aksara.

Arifah Bintarti, Djoko Rahardjo, N. K. W. (2018). No Title. Kajian Kepuasan Mahasiswa Terhadap Layanan Proses Pembelajaran Jarak Jauh Pada Program Studi S-1 Ilmu Komunikasi, 379-399. http://repository.ut.ac.id/7969/1/ocs-2018-19.pdf

Arwanda, N. O. D., Hartoyo, H., \& Hartoyo, S. (2013). Kepuasan, Citra, dan Loyalitas pada Lembaga Pendidikan Tinggi: Kasus di Akademi XYZ. Jurnal Ilmu Keluarga \& Konsumen, 7(2), 123-132. Https://Doi.Org/10.24156/Jikk.2014.7.2.123.

Bates, A. W., \& Bates, T. (2005). Technology, e-learning and distance education. Psychology Press. London: Routledge.

Belawati, T. (2003). Penerapan E-learning dalam Pendidikan Jarak Jauh di Indonesia. Cakrawala pendidikan. Jakarta: Universitas Terbuka.

Canton, B. (2004). Dasar-Dasar Publik Relation. Bandung: Remaja Rosdakarya.

Ciptono, F. (2001). Prinsip-prinsip Total Quality Service. Yogyakarta: Andi Offset.

Dietmar K Kennepohl. (2019). Teaching Science at Distance, in Handbook of Distance Education. Third Edition, edited by Grahame Moore.

E Knapp, D. (2000). The Brand Mindset. Yogyakarta: Andi.

Gramer dan Brown. (2006). Loyalitas Pelanggan sebagai Strategi Bersaing. Jakarta: Erlangga.

Jefkins, F. (1998). Public Relations. Edisi ke 5. Jakarta : Erlangga.

Katx, B. (1994). Komunikasi Bisnis Praktis. Penerjemah: Soeharsono. Jakarta: Pustaka Benaman Presindo.

Kotler, P. (2003). Marketing Management, Eleventh Edition. USA: Prentice Hall, Pearson Education International.

Marc J Rosenberg. (2001). E-Learning: Strategies for Delivering Knowledge in the Digital Age. New York: McGraw-Hill.

Michael LeBpeuf, P. D. (1992). Memenangkan dan Memelihara Pelanggan. Jakarta: Pustaka Tangga. 
Rahayu. (2009). Strategi Meraih Keunggulan dalam Industri Jasa. Bandung: Alfabeta. Sihombing. (2002). Pendidikan Berbasis Masyarakat (Jakarta: CV Multifuna (ed.)).

Soleh Soemirat dan Elvinaro Ardianto. (2007). Dasar-Dasar Public Relation. Bandung: Remaja Rosdakarya.

Taylor, Steven. A., Celuch, Kevin, dan G. S. (2004). , The Important of Brand Equity to Customer Loyalty. Journal of Product and Brand Management, Volume 13,

Tim Rektorat. (2012). Laporan Akuntabilitas Kinerja Universitas Terbuka. Jakarta: Penerbit Universitas Terbuka.

Tjiptono, Fandy dan Gregorius, C. (2011). Service, Quality \& Satisfaction. Yogyakarta: Andi Offset.

Utomo, P. D. (2006). Analisis Terhadap Faktor-Faktor Yang Mempengaruhi Loyalitas Konsumen Pada Operator Telepon Seluler. Thesis: Universitas Gadjah Mada.

Weigert, K. M. (1998). Academic Service Learning: Its Meaning and Relevance New Directions For Teaching And Learning. , No. 73, San Francisco: Spring JosseyBass Publishers. 